\title{
A comunidade alemã em Curitiba e a conjuntura da Primeira Grande Guerra $^{1}$
}

\section{The German community in Curitiba and the circumstances of the First World War}

\author{
Sergio Odilon Nadalin*
}

Pamela Fabris**

\begin{abstract}
Resumo
Fundamentado principalmente na imprensa periódica, o artigo pretende problematizar o ambiente de relativa tensão gerado pelas ambiguidades da presença imigrante germânica no Brasil. Da mesma forma, pela repercussão na opinião pública brasileira do embate dos interesses americanos, ingleses, franceses e alemães - face, em grande parte, ao "perigo alemão", provavelmente uma construção francesa, mas amplamente respaldada por parte das elites, como Silvio Romero. Não só devido à presença teutobrasileira, também em Curitiba essas questões eram discutidas: em consequência à escala mundial do imperialismo, não havia lugar no mundo onde não se fazia sentir fortemente a rivalidade entre as potências da época. As informações analisadas permitem observar que a opinião pública brasileira, manifestada em alguns jornais pesquisados, parecia estar dividida, embora as notícias veiculadas por jornais curitibanos, até 1914, fossem geralmente elogiosas à "colônia germânica", após a eclosão da Primeira Guerra Mundial e as pressões para a entrada do Brasil no conflito desencadeou quase que uma unanimidade nacional contra a Alemanha. De todo modo, para resumir a conjuntura, vivenciava-se um embate entre uma imprensa teuto-brasileira, de diversas linhas, e uma imprensa "nacional", o que gerava conflitos de opiniões decorrentes da opinião pública curitibana.
\end{abstract}

Palavras-chave: Conflitos étnicos. Primeira Guerra Mundial. Perigo alemão.

\footnotetext{
${ }^{1}$ A primeira versão deste texto foi apresentada no $54^{\circ}$ Congresso Internacional dos Americanistas, em Viena (Simpósio 666, "Las sociedades latinoamericanas ante la Primeira Guerra Mundial”, 19 de julho de 2012).

* Professor do Programa de Pós-Graduação em História da Universidade Federal do Paraná (UFPR), e pesquisador-bolsista do Conselho Nacional de Desenvolvimento Científico e Tecnológico (CNPq). E-mail: sergion@terra.com.br

* Mestranda no Programa de Pós-Graduação em História da Universidade Federal do Paraná (UFPR). Bolsista Reuni.E-mail: pamfabris@hotmail.com
} 


\begin{abstract}
Based mainly in the periodical press, the article aims to discuss the environment of some tension generated by the ambiguities of German immigrant presence in Brazil. Likewise, the impact on public clash between the interests of the Brazilian, American, British, French and German - face, in large part, to the "German danger", probably a French construction, but widely supported by elites, as Silvio Romero . Not only due to the presence of Teuto-Brazilian, also in Curitiba these issues were discussed: due the consequence of imperialism on a world scale, there was place in the world where there was felt strongly the rivalry between the powers of the time. The information analyzed allow observing that the Brazilian public opinion, expressed in some newspapers surveyed, seemed divided. The information analyzed allow us to observe that the Brazilian public opinion, expressed in some newspapers surveyed seemed to be divided, although the news published by newspapers curitibanos, until 1914, were generally laudatory to the "German Colony" after the outbreak of the First World War and pressures for Brazil's entry in the conflict triggered almost a national unanimity against Germany. Anyway, the outbreak of the First World War and the pressures for Brazil's entry in the conflict generated nearly a national unanimity against Germany. Anyway, to sum up the situation, is experiencing a clash between German-Brazilian press, of various hues, and press "national", which generated conflicting opinions on which thrashed the public Curitiba.
\end{abstract}

Keywords: Ethnic conflicts. World War I. German Danger.

\title{
Introdução
}

\section{Gustav Hermann Strobel}

O personagem central deste texto é, muito mais, um pretexto para se contar uma história. Estamos nos referindo a Gustav Hermann Strobel, ${ }^{2}$ um

\footnotetext{
${ }^{2}$ De acordo com suas memórias, nasceu em Dresden, em 1849. Faleceu em Curitiba, em 1933 (Arquivo da CELC-UP). A família e a linhagem Strobel em Curitiba já foram "fios condutores" de pesquisa com resultados publicados ou em vias de publicação: BIDEAU, Alain; NADALIN, Sergio Odilon. Comment des Luthériens allemands sont-ils devenus des Brésiliens? Un essai méthodologique. In BRUNET, Guy et al (éds.). Les minorités - Minorities. Une démographie culturelle et politique, $\mathrm{XVIII}^{\mathrm{e}}-\mathrm{XX}{ }^{\mathrm{e}}$ siècles. A Cultural and Political Demography, 18th-20th Centuries. Berna: Peter Lang, 2004; MACHADO, Cacilda da Silva; NADALIN, Sergio Odilon. Memória individual e discurso social. Relatos de um imigrante: Curitiba (Brasil), segunda metade do século XIX, primeira metade do século XX. Rio de Janeiro: UFRJ; Curitiba: UFPR. Comunicação apresentada no Segundo Congreso da Associación Internacional Areia. América Latina-Europa: (auto)biografias de emigrantes entre cultura oral, escritura e representación. Roma (Itália), 29 a 31 de outubro de 2012; NADALIN, Sergio Odilon, 2007. João, Hans, Johann, Johannes: dialética dos nomes de batismo numa comunidade imigrante. História UNISINOS. São Leopoldo: Universidade do Vale do Rio dos
} 
imigrante no Brasil, e à comunidade etnocultural da qual era partícipe. Pretendemos salientar como, no período demarcado (1890 a 1919), este nosso ator estava mergulhado no ambiente de relativa tensão gerado pelas ambiguidades da presença imigrante germânica no Brasil e no Cone Sul do continente; e, da mesma forma, pela repercussão na opinião pública brasileira do embate dos interesses americanos, ingleses, franceses e alemães.

\section{Um grupo etnocultural}

Gustav Hermann, seu irmão mais novo e suas irmãs, três delas nascidas em Curitiba, foram todos confirmados na profissão de fé evangélica, na capital do Paraná. Mais do que organizados numa paróquia, os protestantes de origem germânica constituíam o núcleo de um grupo cultural. ${ }^{3}$ Desse modo, não só frequentavam a Igreja: suas crianças eram matriculadas na escola alemã. Da mesma forma, eram clientes preferenciais de estabelecimentos comerciais fundados por imigrantes (padarias, armazéns, moinhos, olarias, ferrarias, madeireiras etc.), e conviviam cada vez mais com pessoas que falavam melhor o alemão do que o português nas dezenas de Vereine (associações) que proliferavam em Curitiba. ${ }^{4}$

No cotidiano da vida urbana, a inserção e o contato com o 'outro' fortaleceram, no grupo, modos de expressão privilegiados e complementares,

Sinos, 11(1):14-27, jan/abr.; NADALIN, Sergio Odilon. Construindo alteridades: a trajetória de vida de um jovem imigrante no Brasil (Curitiba, segunda metade do século XIX). História: Questões \& Debates. Curitiba: UFPR/APAH, 26(51), jul./dez, 2009, p.181-208.; NADALIN, Sergio Odilon. Construindo alteridades: memórias de um imigrante no Brasil (segunda metade do século XIX). Comunicação apresentada no VI Congresso do Conselho Europeu de Investigações Sociais sobre a América Latina (VI CEISAL), Toulouse, 30 de junho a 3 de julho de 2010. Texto em: http://halshs.archives-ouvertes.fr/docs/00/49/69/18/PDF/SergioNadalin. pdf; NADALIN, Sergio Odilon. A constituição das identidades nacionais nos territórios de imigração: os imigrantes germânicos e seus descendentes em Curitiba (Brasil), na virada do século XX. XVI CONGRESSO AHILA, 2011. San Fernando, 6-9 de setembro de 2011. Texto inédito; MACHADO, Cacilda da Silva, 1997. A família e o impacto da imigração (1854-1991). Revista Brasileira de História, 17(34), disponível em http:// www.scielo.br/scielo.php?script=sci_arttext\&pid=S0102-01881997000200004, acessado em 24 de abril de 2012; MACHADO, Cacilda da Silva. De uma familia imigrante: sociabilidades e laços de parentesco. Curitiba: Aos Quatro Ventos, 1998.

${ }^{3}$ Mencionando a importância do luteranismo para o Deutschtum, Giralda Seyfert enfatiza que "o grupo étnico e o grupo religioso praticamente se confundem, se interpenetram". SEYFERTH, Giralda. Nacionalismo e identidade étnica. Florianópolis: Fundação Catarinense de Cultura, 1981. p.142. Os alemães de origem católica constituíam minoria, embora se possa, generalizando, incluí-los no grupo étnico.

${ }^{4}$ Gustav Hermann Strobel foi associado fundador da sociedade dos artífices alemães em Curitiba (Handwerker Unterstützungs Verein) e, também, membro da Loja Maçônica Concórdia IV e do Sängerbund. Seu irmão Robert Emil, também carpinteiro, foi igualmente maçom, e Vice-Presidente na primeira diretoria do Handwerker, quando da sua fundação, em 19 de julho de 1884, e várias vezes membro da diretoria (Vorsteher) do Deutscher Sängerbund, em 1890, 1891, 1895 e 1903. 
permitindo laços permanentes de viva solidariedade. ${ }^{5}$ Da outra parte - ou seja, na perspectiva do 'outro' -, a presença imigrante dava um novo colorido à cidade. Os curitibanos viam a inovação das técnicas, e a renovação da paisagem agrícola, contribuindo para que fossem atingidos, pelo menos na Capital e em seus arredores, os objetivos da política provincial da colonização realizada principalmente por imigrantes.

Ao escrever suas memórias, não é surpreendente que, de modo até redundante, Strobel enfatizasse as virtualidades do "trabalho alemão". Seu texto, também, está eivado de elogios sobre a superioridade dos imigrantes em relação aos nacionais. ${ }^{6}$ Ele é bastante comedido, no entanto, comparado aos elogios de órgãos da imprensa curitibana, como a admiração exteriorizada pela matéria publicada no Diário da Tarde:

Quando a grande e disciplinada força de vontade [do povo alemão], ahi não estão a unificação do Imperio, a expansão da industria e o desenvolvimento do commercio a demonstrar que os allemães sabem o que querem e ainda mais, reduzem a factos, objectavam as suas volições. Mas si não bastam estas provas, temo-las nós, dentro da nossa cidade, testemunho eloqüente e incontestável. Vede o nosso progresso actual, os grandes bazares, os grandes prédios e comparae esta condição com a que existia em 1835, quando a vontade enérgica de um homem, que mal sabia subscrever seu nome, mas que nem por isso deixa de ser um benemérito - o Barão de Antonina, conseguiu trazer para as mattas do Rio Negro as primeiras levas dos colonos allemães (...).?

Mas, de outro lado, e para além daquilo que a historiografia enfatiza sobre a contribuição dos imigrantes e descendentes para a urbanização da capital da Província, e do respeito que muitos brasileiros tinham pelos estrangeiros, esses também começavam a causar certo mal-estar entre seus anfitriões. Não estamos nos referindo somente ao contexto internacional que repercutia no Brasil, sobre o qual abriremos uma seção adiante. O que queremos grifar: se a influência "imigrante" traduzia em parte as mudanças na cidade, com sua presença econômica, física e espiritual... ${ }^{8}$, esses "sinais inequívocos de progresso" - como avaliava Thomas Bigg-Wither, na sua segunda visita à Curitiba - caminhavam pari passu com certo endurecimento

\footnotetext{
${ }^{5}$ BLANCPAIN, Jean-Pierre. Migrations et mémoire germaniques en Amérique Latine. Strassbourg: Presses Universitaires de Strassbourg, 1994, p. 184.

${ }^{6}$ STROBEL, Gustav Hermann. Relatos de um pioneiro da imigração alemã. Curitiba: IHGEP, 1987.

${ }^{7}$ Diário da Tarde, Curitiba, 4/11/1905.

${ }^{8}$ RIBEIRO, Boanerges. Protestantismo no Brasil monárquico, 1822-1888: aspectos culturais de aceitação do protestantismo no Brasil. São Paulo: Pioneira, 1973.
} 
das representações sociais e das tensões urbanas. ${ }^{9}$ Assim, por exemplo, se as autoridades eram coniventes e as leis do país toleravam a religião protestante, "já não a toleravam muito dos padres, bem como a população por eles influenciada". ${ }^{10}$ Não era só a questão religiosa, pois se acusavam os imigrantes e descendentes de "inassimiláveis", assunto aquecido pela querela entre a cada vez mais atuante imprensa teuto-brasileira e diversos jornais do país.

Ao fim e ao cabo, de um grupo afinado pelas semelhanças que os uniam, os alemães em Curitiba desenvolveram, com o tempo, um "processo de seleção de traços culturais dos quais os atores se apoderam para transformá-los em critérios de consignação ou de identificação com um grupo étnico". ${ }^{11}$

Dessa forma, ao observar as razões de uma maior delimitação das fronteiras entre os alemães e descendentes e a sociedade hospedeira, Strobel esclarece, à sua maneira que

nos primeiros anos da chegada dos imigrantes alemães a Curitiba, os brasileiros admiraram a tenacidade no trabalho e os novos conhecimentos que foram introduzidos nas diversas atividades por eles exercidas. Mas, com o passar dos anos, quando os imigrantes começaram a progredir, aos poucos adquirindo propriedades, elevando o padrão de vida, como também possuindo os direitos de cidadãos brasileiros - e com isso reivindicando o direito de voto - desagradaram certas castas de nativos daqui da terra. ${ }^{12}$

Além dos fatores já mencionados, enfatizamos que esses fatos se explicam pela inserção dos imigrantes e de seus filhos na sociedade curitibana, e pela situação de contato resultante. Da mesma forma, pela constituição do Reich em 1870 e a influência cada vez mais forte do nacionalismo alemão - incentivando a emigração alemã e a propaganda pangermanista ${ }^{13}$, o que

\footnotetext{
${ }^{9}$ BIGG-WITHER, Thomas Plantagenet, 1974. Novo caminho no Brasil meridional: A Província do Paraná. Três anos em suas florestas e campos, 1872/1875. Rio de Janeiro: J. Olympio; Curitiba: Universidade Federal do Paraná, p. 323.

${ }^{10}$ RIBEIRO, p. 91.

${ }^{11}$ POUTIGNAT, Philippe; STREIFF-FENART, Jocelyne. Teorias da etnicidade. São Paulo: Unesp, 1998.

${ }^{12}$ STROBEL, p. 135.

${ }^{13}$ É preciso lembrar que, a partir da unificação alemã, parcela dos imigrantes que chegavam, os denominados Reichdeutsch (alemães do império), foram, em especial, veículos de um novo nacionalismo, fato que se dava concomitante à chegada, ao Brasil, da Igreja Evangélica Alemã e de um protestantismo que cada vez mais impregnava os valores teutos. SANTANA, Nara Maria Carlos de,. Colonização alemã no Brasil: uma história de identidade, assimilação e conflito. 2010. Dimensões, v.25, p. 235-48.
} 
indicava possíveis interesses do Império Alemão na região ${ }^{14}$, principalmente a partir dos anos 1890.

\section{Entre o "nós" e os "outros", o perigo alemão}

Devido à escala mundial do imperialismo, não havia lugar no mundo onde não se fazia sentir fortemente a rivalidade entre as potências da época. Diminuindo o foco, isso era evidente no Cone Sul (leia-se, principalmente no nosso caso, o Brasil Meridional), como veio a mostrar o episódio Panther, que mencionaremos adiante.

A rápida expansão da ideia de um “perigo alemão" não estava só vinculada à propaganda antigermânica dos países rivais. A presença do Império Alemão, por toda parte, fazia-se sentir, porque o país, ao contrário das outras nações européias, chegara atrasado à corrida colonialista; assim, vinha aguerrida, a diplomacia imperial reivindicando um lugar proporcional à medida do país por ela representado, seduzindo ou intimidando - e não deixando indiferentes. ${ }^{15}$

Nesse contexto, a imigração permanecia praticamente sem solução de continuidade, assinalando certa estabilidade na segunda metade do século XIX. Essa continuidade rompeu-se com o aumento crescente do fluxo na virada do século, até a eclosão da Guerra de 1914. No total, entre 1819 e 1919, ingressaram no país cerca de 130 mil indivíduos. ${ }^{16}$ Destes, principalmente a partir da década de 1850, uma parcela pequena estabeleceu-se na região de Curitiba, na Província do Paraná. Como a maioria era protestante, organizaram-se numa paróquia de confissão evangélica luterana, inaugurada em 1866.

Não eram muitos, se comparados com o total dos imigrantes ou com o número de habitantes da região de Curitiba ${ }^{17}$; esses poucos, no entanto, nas

\footnotetext{
${ }^{14}$ A historiografia enfatiza que muitas vezes um alegado interesse "expansionista" alemão residia na tentativa de reservar para si um mercado preferencial. De qualquer modo, este interesse também poderia compreender ideias de anexação, como em certos meios pangermanistas mais radicais. MAGALHÃES, Marionilde Dias Brepohl de. O pangermanismo e o nazismo; a trajetória alemã rumo ao Brasil. Campinas: UNICAMP/FAPESP, 1998; SEYFERT, Giralda. Identidade étnica, assimilação e cidadania: a imigração alemã e o Estado Brasileiro. XVII Encontro Anual da ANPOCS, Caxambu, MG, 22-25 outubro de 1993. http://www. anpocs.org.br/portal/publicacoes/rbcs_00_26/rbcs26_08.htm Acesso em: 1.일. de janeiro de 2007.

${ }^{15}$ BLANCPAIN, op. cit.

${ }^{16}$ NADALIN, Sergio Odilon. Imigrantes de origem germânica no Brasil. Ciclos matrimoniais e etnicidade. Curitiba: Quatro Ventos, 2000.

${ }^{17}$ Romário Martins, em Quantos somos e quem somos, tentou realizar uma contabilidade da população livre e dos imigrantes no Paraná. MARTINS, Romário. Quantos somos e quem somos. Dados para a história e a estatística do povoamento do Paraná. Curitiba: Empresa Gráfica Paranaense, 1941.
} 
festividades e manifestações, eram bastante efusivos. A respeito, algumas décadas mais tarde a imprensa local dava o seu testemunho. Note-se, por exemplo, como o Diário da Tarde noticiava sobre o aparato organizado na capital do Estado pelas associações teuto-brasileiras, na recepção aos oficiais e marujos de uma "canhoneira" alemã, fundeada em Paranaguá.

Como fora annunciado, hoje ao meio dia, em comboio especial chegaram a esta capital sete officiaes e 40 marinheiros do vaso de guerra allemão Panther. Ás 11 3/4 começaram a affluir á praça Euphrasio Correia grandes massas populares, umas antecedendo, outras acompanhando as escolas da Communa [evangélica] e dos Franciscanos, que encorporadas, com commissões das sociedades Saengerbund e Thalia áquella hora formaram em dupla ala em frente á estação. A fanfarra do $14^{\circ}$ regimento de cavallaria puchava o préstito..$^{18}$

Um instantâneo do evento, publicado em $1917,{ }^{19}$, retrata a animação dos que recepcionaram os representantes da marujada e dos oficiais do navio de guerra, em Curitiba; traduzindo a imagem em palavras, "era grande o regosijo da laboriosa colônia allemã, notando-se nos semblantes dos subtidos (sic) do Kaiser, visível satisfação". ${ }^{20}$

Pelo menos para o jornal em referência, a visita dos marujos do Panther, "verdadeiros embaixadores itinerantes", ${ }^{21}$ também era motivo para louvar o povo alemão e sua nação de origem:

A história do poderoso império da Allemanha, nestes últimos decennios, é como a propagação da luz: quer intellectual, quer economicamente a grande confederação desprende seus raios luminosos rectilincamente e alcança os fins patrióticos que visa. Mas é a luz, esse phanal das almas, essa que emana da sciencia, do estudo e do gênio e que irradia, também no circulo humano, como um sol sem manchas, o ideal supremo dos descendentes dos bárbaros do norte, que o historiador romano pinta com as longas e flavas cabelleiras. E foram esses homens das frigidas selvas, onde tardio e lento o evoluir da

\footnotetext{
${ }^{18}$ Diário da Tarde, Curitiba, 4/11/1905.

${ }^{19}$ SCHÜLER, Heinrich. Brasilien: ein Land der Zukunft. Leipzig/Stuttgar: Deutsche Verlags-Anstalt, 1917.

${ }^{20}$ Diário da Tarde, Curitiba, 4/11/1905.

${ }^{21}$ COSTA, Vidal Antonio de Azevedo. Olhares mutantes: faces antagônicas na imagem da máquina no começo do século XX - o caso da canhoneira alemã "Panther". História: Questões \& Debates, Curitiba, Editoria UFPR, 1998, Ano 14, v. 29, p. 141-172. O Panther, em seguida, navegou até fundear no Porto de Itajaí, em Santa Catarina. Uma ação do seu comandante (parente próximo do Kaiser Guilherme II) e dos seus marinheiros desencadeou uma crise de repercussão internacional, em novembro de 1905. O mesmo navio foi protagonista de outras ações no Haiti, São Domingos (1900) e na Venezuela (1902); e, principalmente, em Tanger (1905) e Agadir (1911). O roteiro cronológico referente às questões com a Alemanha Imperial e, principalmente, o incidente em Itajaí, foi documentado por José Joffily. JOFFILY, José. o Caso Panther. Rio de Janeiro: Paz e Terra, 1998.
} 
civilização, os que lançaram sobre as ruínas do império dos cezares, os alicerces dos estados modernos. ${ }^{22}$

Na ocasião, o mesmo diário também exaltava as virtudes do imigrante e colono germânico, sem mencionar, nem de longe, o que se dizia do caráter inassimilável do alemão. Ao contrário, essa era, até, uma qualidade, se atentarmos para a comparação feita com o "povo inglês":

A colônia allemã; numerosa, intelligente, emprehendedora, profundamente sympathica ao meio brazileiro, mas mantendo sempre seus hábitos em geral, era e é a que se destina, no futuro dos Estados do sul, a deixar vestígios de sua influencia. [...]. É sabido que o typo inglez também degenera na India, dizem que pela influencia muito preponderante do meio physico, independente de qualquer cruzamento e a despeito da escrupulosa conservação de todos os hábitos moraes, intellectuaes e práticos, levadas da mãe pátria. [...]. 0 allemão, nos Estados do sul do Brazil... conserva-se moral e physicamente um perfeito allemão. ${ }^{23}$

Resumindo com as palavras do historiador acima referido, ainda com referência ao Panther, "a passagem simbólica de um navio de guerra alemão torna-se pretexto para afirmar não apenas a superioridade germânica, mas também aquela que os germânicos conferem a todas as regiões que escolhem para habitar". ${ }^{24} \mathrm{E}$, como vimos, a opinião do Diário parecia endossar o poderio alemão, seja militar e naval, seja ao se considerarem as virtudes da cultura teuta.

Quanto ao jornal A República, também de Curitiba, no dia 4 de novembro saudava os "amigos de além-mar", os "filhos illustres de outras plagas", acolhidos pela "generosa alma do povo paranaense", que

se entreabre, em palpitações de hospitaleiro carinho, para receber a heróica marinhagem allemã, os fortes guerreiros do mar, que desde as paragens luminosas do Equador vêm percorrendo o viridente littoral da Patria Brazileira e admirando a imponência de tantas grandezas reunidas pela mão potente do Creador n'este priviligia do pedaço do continente americano,eterno assombro de todos os visitantes, que mal podiam comceber o espectaculo d'uma natureza mais prodigiosa a dormitar á luz serena e doce das constellações austraes. Recebemol-os com carinho, não porque sejam os representantes officiaes de uma potencia formidável, mas porque concretisam em si a representação pacifica d'uma raça que tanto há se esforçado pelo desenvolvimento do nosso comercio e industria, e consequentemente pelo progresso deste Estado que notável impulso tomou desde que aqui aportaram

\footnotetext{
${ }^{22}$ Diário da Tarde, Curitiba, 4/11/1905.

${ }^{23}$ Idem, sem grifo no original.

${ }^{24}$ COSTA, p. 156.
} 
as levas teutônicas, trazendo para o cadinho de elaboração da raça néobrazileira o seu profícuo contingente..$^{25}$

Pensamos que não há manifestações de simpatia mais eloquentes do que essas, declaradas explicitamente pelos dois diários curitibanos.

$$
* * *
$$

Assim, de muitas maneiras a "colônia" marcava presença na sociedade curitibana. Porém, o impacto da colonização tinha uma repercussão política muito mais importante não só no Brasil Meridional, mas também no continente americano.

De modo que, agora, é necessário ampliar novamente o enfoque: a época constitui, como mencionamos, uma fase particularmente especial na história do imperialismo, colorido pelos movimentos "pan" e nacionalistas - e, de certa forma, por aquilo que aqui se poderia denominar de "monroísmo"26 - encaminhando, como é sabido, para engessadas políticas de alianças que desembocaram na Guerra de 1914. Embutida na questão estava a ação das organizações nacionalistas alemãs que visavam propagar as ideias do Deutsches Volkstum (nacionalidade alemã) entre imigrantes germânicos ${ }^{27}$

Nesse âmbito, via-se com naturalidade, por uma parcela da opinião pública alemã, a manutenção da nacionalidade alemã por parte dos membros das colônias implantadas, por exemplo, no Sul do Brasil. Recuemos alguns anos, até 1899: no dia 7 de maio, o jornal A República publicara um telegrama oriundo de Bremen, porto e cidade, que muito teria se beneficiado com o transporte de imigrantes pelas companhias de navegação:28

Bremen,7: Imprensa aconselha o governo a hastear a bandeira allemã nos territórios do sul do Brazil occupados pela companhia hanseática ${ }^{29}$, onde a colonisação abarca área maior que a do Grão

\footnotetext{
${ }^{25}$ A República, Curitiba, 4/11/1905.

26 “Nos Estados Unidos surgiram diversas publicações, de caráter alarmista, denunciando os interesses pangermânicos no Sul do Brasil - região que passou a ser chamada de ‘Little Germany' numa alusão às possíveis tentativas futuras de transformá-la numa verdadeira colônia alemã. As 'colônias alemãs' ganharam, assim, uma notoriedade internacional, em função do jogo de interesses imperialistas de norte-americanos, alemães, ingleses e franceses". SEYFERT, Identidade étnica, ... op. cit., p. 49.

${ }^{27}$ GOLLWITZER, Heinz, s/d. O imperialismo europeu, 1880-1914. Lisboa: Verbo, s/d. (original publicado em língua inglesa em 1969). p. 62-63; BLANCPAIN, Jean-Pierre, op. cit., p. 267-269.

28 Por exemplo, a Norddeutsche Lloyd foi a maior companhia transatlântica da Alemanha, responsável pela entrada de 47 mil pessoas no Brasil a partir de 1890. SANTANA, op. cit., p. 235-48.

${ }^{29}$ A respeito da Sociedade Colonizadora Hanseática, ver RICHTER, Klaus. A Sociedade Colonizadora Hanseática de 1987 e a colonização no interior de Joinville e Blumenau. Florianópolis: Ed. da UFSC. Blumenau: Ed da FURB, 1986.
} 
Ducado Oldemburgo. Accrescentam os jornaes que a doutrina de Monroe caducou com a occupação das Filippinas pelos americanos. ${ }^{30}$

Imaginando que, por "imprensa" deveria se ler jornais de Bremen e, por "governo", o alemão, dessa feita o Diário da Tarde reagiria de outra forma. Reportava que, em consequência dessa rápida notícia, na noite anterior "um grupo de moços entusiastas percorreram as ruas de Curitiba protestando os seus sentimentos de patriotismo..." (10/5/1899). O mesmo jornal, tentando firmar sua independência em relação aos lados beligerantes, três dias mais tarde ainda comentava:

Firma-se a lógica dos jornais de Bremen, em não haver mais motivos para a América reclamar por si o principio enunciado por Monroe na memoravel mensagem em que disse ser a América um corpo que não permitirá jamais qualquer tentativa da Europa contra o território americano. Esse motivo, diz, cessou desde que os EUA se expadiram até as Philipinas. O Diário exprime nestas linhas, as provas de amor a Pátria Brazileira, mas não crê que por parte da Alemanha se dirija qualquer tentativa contra a integridade do territorio brazileiro, em cuja parte do sul tem sido e são os alemães um elemento de progresso e ordem. ${ }^{31}$

Não muitos dias mais tarde - sob o título "O telegrama de Bremen" -, A República traduz e publica um editorial da Gazeta Polaca, ${ }^{32}$ também de Curitiba. Trata-se de "patrióticas declarações que n'elle se faz a briosa e laboriosa colônia polaca" sobre o tema que inquietava a mídia da época, "assunto de alta monta e que reclama a attenção, o patriotismo e civismo do povo brasileiro" (Diário da Tarde, 31/5/1899). Assim, para alguns já preocupava o avanço alemão: o discurso que segue amplia essas preocupações, juntando às questões étnicas vislumbradas aqui e ali, por uma ou outra nota e por algumas opiniões, o ingrediente das relações polono-alemãs, transportadas para o Brasil com a imigração:

Fala-se que a esquadra allemã vem seguindo para o sul e que acha-se actualmente em Lisboa. Esta noticia, junta aos sensacionaes telegrammas de Bremen, poderia ser considerada como prophetica de incidentes importantes

\footnotetext{
${ }^{30}$ A República, Curitiba, 7/5/1899. O mesmo telegrama também foi publicado pelo Diário da Tarde, no mesmo dia.

${ }^{31}$ Diário da Tarde, Curitiba, 10/5/1899, sem grifo no original No mesmo dia 10, voltando ao caso do telegrama de Bremen, o Diário da Tarde informava que, também em Berlim sustentava-se a ideia de hastear bandeiras alemãs no Sul do Brasil, firmando-se nos mesmos princípios de que a doutrina Monroe não deveria mais ser respeitada pelas nações européias.

32 “Gazeta Polska w Brazylii” (1892-1941), MALCZEWSKI SChr, s/d, Zdzislaw. A imprensa da comunidade polônica brasileira. Disponível em: http://www.polonicus.com.br/pt/biblioteca/Aimprensa.html, acessado em 28 de março de 2012.
} 
para próximo futuro, si conhecida ficasse sua verdadeira origem. Queremos porem acreditar que taes noticias sejam falsas, e queremos sinceramente, que esta tempestade, imminente no horisonte do livre Brazil, mostrasse apenas um canard de jornaes ou o simples 'pio desiderio' de algum rabiscador prussiano. Mas de qualquer forma que a situação se desenvolva, devem os brasileiros saber que em nós os polacos, tem e terão sempre francos e verdadeiros amigos, com os quaes em caso de precisão sempre poderão contar. A política de roubos e mentiras dos impérios visinhos custaram a nossa nação, há mais de cem annos, a perda de sua liberdade e autonomia, e hoje, em nossa própria pátria, temos que supportar a oppressão nacional, religiosa, política e econômica. Perdida assim nossa liberdade e autonomia, sabemos portanto mais apreciar o valor d'ella, e já algumas vezes fizemos revolução armadas para libertar-nos do jugo estrangeiro. ${ }^{33}$

Anos mais tarde, as ações do referido Panther no Haiti e em São Domingos, em 1900, na Venezuela em 1902, em Tanger, março de 1905 (agora já no contexto da série de crises que tiveram como foco o Marrocos), ${ }^{34}$, e em Itajaí em novembro do mesmo ano e pouco depois da visita a Paranaguá, pareciam o cumprimento de um presságio veiculado pela Gazeta Polska. Amplamente noticiadas pela imprensa nacional e internacional, a sem-cerimônia das ações alemãs não contribuía para amenizar o problema que se discutia nas matérias publicadas nos jornais - a esse respeito, a opinião pública brasileira parece ter se manifestado muito contraditoriamente e a historiografia mostra que parte de suas elites políticas não tinha simpatia pelo Reich. ${ }^{35}$

Assim, o mesmo diário A República, por ocasião da visita da canhoneira a Paranaguá, elogiava: a "poderosa marinha allemã" era "valente e heroica na guerra, quanto amistosa e franca na paz". Dessa forma,

a marinha imperial não se limita á missão de vigilância com que as nações coloniaes da Europa costumam investir as respectivas esquadras em longínquas paragens. Assim é que percorrendo incessantemente os mares, em viagens de nímia cortezia, os navios allemães estreitam as relações entre Allemanha e os demais paizes, accumulando sobre esse povo de tão bellas e heróicas tradições a sympathia, que mais cresce e se desenvolve á medida que

\footnotetext{
${ }^{33}$ A Republica, Curitiba, 31/5/1889.

${ }^{34}$ Ver a cronologia das crises entre 1903 e 1914, publicada em "The Maroccan crisis", s/d. Assinale-se que o Panther também foi primeiro personagem em Agadir, no início de julho de 1911.

${ }^{35}$ ARANHA, José Pereira da Graça. Brasil e pangermanismo. In: CHÉRADAME, André. O plano pangermanista desmascarado. A temível cilada berlineza da "partida nulla”. Rio de Janeiro: Garnier, 1917. p. III-XXXII.; OLIVEIRA, Lúcia Lippi. A questão nacional na Primeira República. São Paulo: Brasiliense em co-edição com o Programa Nacional do Centenário da República e bicentenário da Inconfidência Mineira; co-edição MCT/ CNPq), 1990; VOGT, Olgário Paulo. O alemanismo e o "perigo alemão" na literatura brasileira da primeira metade do século XX. Signo, Santa Cruz do Sul, 2007.
} 
se consolida a obra admirável de 1870: a unidade germânica, representada no actual momento pelo homem de maior prestigio histórico e político: o Kaizer. ${ }^{36}$

Para alguns (inclusive membros importantes do governo), as boas relações com a Alemanha Imperial eram muito importantes. ${ }^{37}$ Depois dos "incidentes" de Itajaí, provavelmente ampliados pela mídia, o jornal florianopolitano O Dia informava que seria oferecido um baile à "briosa oficialidade" do Panther, que visitava Florianópolis..$^{38}$ Alguns meses depois, o Semanário Os Annaes, publicado no Rio de Janeiro, a respeito do caso Panther colocava panos quentes:

Mas a coisa não fora tão feia quanto pintaram o governador de Santa Catarina e outros informantes, desvairados pela primeira impressão, quasi sempre enganadora, dando tons pejorativos exaggerados aos mais vulgares, aos mais naturaes, aos mais innocentes factos deste mundo. Pelas notas officiaes publicadas na imprensa e no Diário Official, ficamos sabendo que não houve violação do nosso território, porque jamais poderia ter tamanho alcance o desembarque de uma patrulha de marinheiros allemães para procurar, com as mais cândidas intenções, um camarada desertor. ${ }^{39}$

Para outros, todavia, desconfiava-se das pretensões imperialistas do Império Germânico, que tinha como um dos braços as organizações pangermânicas; e mais, não olhavam com bons olhos a natural simpatia que

\footnotetext{
${ }^{36}$ A República, Curitiba, 4/11/1905.

${ }^{37}$ É preciso acrescentar que, ainda às vésperas da Guerra, o Brasil entretém excelentes relações com os países beligerantes. Seus principais parceiros comerciais europeus são a Grã-Bretanha e a Alemanha, país que mais compra produtos do Brasil, depois dos Estados Unidos. Em consequência, "as relações diplomáticas entre o Brasil e a Alemanha são normais e absolutamente satisfatórias". Mesmo a crise desencadeada pelas ações do Panther em Itajaí, em vez de reverter as relações entre os dois países, "pelo contrário, serviu para estreitar as relações entre os dois governos". SANTOS, Norma Breda dos. Relações Brasil-Alemanha, 1914-1919. MENEZES, Albene Miriam F.; e KOTHE, Mercedes Gassen (orgs). Brasil-Alemanha, 1827-1997. Perspectivas Históricas; 170 anos da Assinatura do Primeiro Tratado de Comércio e Navegação (Anais do II Seminário de Estudos Teuto-Brasileiros, Brasília, 1997). Brasília: Thesaurus. 1997. p. 41-47.

${ }^{38}$ JOFFILY, op. cit., p. 28.

${ }^{39}$ OS ANNAES. Semanário de Litteratura, Sciência, Arte e Industria. Rio de Janeiro, 18 de janeiro de 1906. Anno III. N. 66. Disponível em: http://www.brasiliana.usp.br/bbd/handle/1918/060047-066\#page/1/ mode/1up, acessado em 24 de abril de 2012. p. 33.
} 
tinham as colônias alemãs à bandeira do Império, ${ }^{40}$ o respeito ao Kaiser ${ }^{41} \mathrm{e}$, por tabela, à propaganda dos (ultra)nacionalistas pan-germânicos desenvolvida nas colônias alemãs. ${ }^{42}$

Em 1906, Silvio Romero ${ }^{43}$ também acusava o problema.$^{44} \mathrm{Na}$ sua brochura "O allemanismo no Sul do Brasil: seus perigos e meios de os conjurar, denunciava o terreno preparado por grupos compactos para a expansão do Deutschtum, "formando colônias cheias de cidades e vilas puramente germânicas." ${ }^{45}$ Eram como "ilhas", faltando-lhes, "para se separarem de nós (...), duas condições apenas: uma população maior, e que essa população se espalhe a ponto de ligar entre si, mais ou menos intensamente, os diversos núcleos coloniais dos três Estados meridionais". ${ }^{46}$

$\mathrm{O}$ autor apoiava-se em parte numa matéria publicada pelo Jornal do Commercio ${ }^{47}$, intitulada "Alemães no Brasil", que resumia a questão que tanto o preocupava:

\footnotetext{
${ }^{40}$ Sobre o tema das bandeiras, lembramos a repercussão do "telegrama de Bremen", já mencionado anteriormente. Mencionemos, ainda, o comentário publicado no Diário da Tarde, um mês antes do episódio, mostrando não ter opinião a respeito da questão do símbolo nacional alemão: o jornal referia-se à inauguração do novo prédio da Sociedade de Tiro (Schuetzenverein) em Curitiba: "Passamos dahi, a observar o salão que occupa a maior parte do prédio. Estava ornado com gosto e arte. De todos os lados pendiam cortinas com as cores da bandeira allemã. Nas paredes havia profusão de diversos ramos e folhas de palmeiras entrelaçadas, quadros allegóricos, flores, etc. [...]. Logo a entrada fica um compartimento à guiza de coreto e que serve para colocação da música. No alto deste coreto está um escudo da Prússia" (Diário da Tarde, Curitiba, 3/4/1899).

${ }^{41}$ As escolas alemãs costumavam organizar festejos relacionados ao Kaiser. Foi assim que as irmãs da Divina Providência, todas alemãs, organizaram a festa do jubileu do Imperador, em 1916, "comemorado através de um programa especial no qual as nossas crianças cantavam, dançavam e recitavam poesias no palco da escola, tendo a presença do cônsul alemão." (Crônicas das Irmãs da Divina Providência, Curitiba, 1895-1944).

${ }^{42}$ A Alldeutscher Verband pretendia encorajar os Reichdeutsche e alógenos de origem germânica a se unir para servir, para além dos seus próprios interesses, os do Império Alemão. BLANCPAIN, op. cit., p. 267.

${ }^{43}$ A respeito de Sílvio Vasconcelos da Silveira Ramos Romero, ver MORAES Filho, Evaristo de. O pensamento político-social de Silvio Romero. In: ROMERO, Silvio. Realidades e ilusões no Brasil. Parlamentarismo e Presidencialismo e outros ensaios. Petrópolis: Vozes, 1979. p. 29-53. In: ROMERO, Silvio. op. cit., p. 229-260.

${ }^{44}$ De acordo com Olgário Vogt, "em 1906, ao editar o opúsculo O allemanismo no Sul do Brasil, Sílvio Romero desfecha um dos mais extremados e virulentos ataques contra a forma de vida e a organização social da população de ascendência germânica existente no Brasil Meridional.” VOGT, op. cit., p. 225-258.

${ }^{45}$ apud ROMERO, 1996, p. 240.

${ }^{46}$ ROMERO, op. cit., p. 254.

${ }^{47}$ Diário fundado no Rio de Janeiro em 1827. A respeito da tese do perigo alemão, Silvio Romero apoiava-se em uma série de fontes francesas, inglesas e norte-americanas, embora sem criticá-las convenientemente (VOGT, op. cit., p. 228).
} 
os colonos alemães apresentam nos Estados do sul o curioso fenômeno de uma população à parte que vive sobre si, que se administra e se governa, onde domina a cultura alemã, onde o espírito alemão prevalece e é alimentado, de geração em geração, pelas condições do meio, pela prática da religião, que é exercida por sacerdotes alemães, pelo uso da língua, que é exclusivamente alemã no povo e nas únicas escolas existentes, onde o ensino é ministrado em alemão, por professores alemães, mandados vir da Europa à custa dos colonos ou subvencionados pelo governo imperial. ${ }^{48}$

Por conseguinte, e de maneira nenhuma querendo polarizar em termos de Rio de Janeiro versus Curitiba, o que era louvado pelo Diário da Tarde e, mesmo, pela A República, na capital paranaense em novembro de 1905, era execrado pelo Jornal do Commercio, no Rio de Janeiro, mais ou menos na mesma época.

O jornalista e historiador paranaense Romário Martins, muitos anos mais tarde e num contexto agravado pelo que estava acontecendo na Europa, repisou o mesmo tema das "ilhas" étnicas e econômicas sem ligação com o "continente" nacional. ${ }^{49}$ Porém, na virada do século XX, ainda jovem, já criticava a imigração alemã em massa, dirigida quase sempre para as regiões coloniais do Sul. O que era valorado por alguns, para ele era inquietante, pois,

o allemão, com muita pouca excepção, continúa no Brasil sendo allemão até a $2^{\mathrm{a}}$. e $3^{\mathrm{a}}$. geração. Não aprende a língua official, não se dá com os nossos habitos, não se liga a nós por laços de espécie alguma, e quando a imprensa germânica investe, ladrindo, contra nós, elle a applaude com enthusiasmo. ${ }^{50}$

Até então, o autor critica, censura, denuncia..., mas não ultrapassa as medidas. No entanto, após considerações a respeito da obrigatoriedade do ensino da língua portuguesa nas escolas brasileiras e do desrespeito a ela pelas escolas alemãs, entorna o caldo, no mesmo texto:

Esta é que é a verdade, na qual ninguém se preoccupa ostensivamente, mas que é preciso que os bons Brazileiros tenham muito em vista, afim de poderem affirmar, agora e sempre, que isto é nosso e que nos havemos de manter na posse do nosso território, ou por bem ou por mal; ou recebendo generosamente o estrangeiro e dando-lhe trabalho e fortuna quando nos

\footnotetext{
${ }^{48}$ Apud ROMERO, op. cit., p. 247.

${ }^{49}$ MARTINS, op. cit., p. 56.

${ }^{50}$ MARTINS, Romário. Uma viagem pelo Paraná. In: ALMANACH do Paraná para 1900. Curitiba, Livraria Econômica, 1900, p. 235.
} 
respeite, - ou expulsando-o à bala do nosso território, quando se torne uma ameaça à nossa nacionalidade $!^{51}$

Gustav Hermann Strobel, a seu modo, argumentava contidamente contra todos esses argumentos nas suas memórias:

Não poucas vezes os jornais publicavam artigos atacando gratuitamente os alemães. Os redatores e responsáveis não deveriam dar guarda a estas provocações, pois essas atitudes só provocam animosidade. Um país como o nosso, que necessita da imigração para o seu desenvolvimento, não deve hostilizar estes que são o sangue novo para o crescimento dessa nação. ${ }^{52}$

De qualquer modo, como nos referimos acima, não eram os jornais paranaenses a "atacar gratuitamente os alemães". o Diário da Tarde publicava, no dia 4 de novembro de 1905, extensa matéria intitulada "Germânia", ao recepcionar a tripulação do Panther, que então visitava Curitiba. Replicava com tintas de emoção o valor dos alemães, unificando o Império, expandindo sua indústria e desenvolvendo o comércio. Juntando provas, mencionava o progresso atual da capital paranaense, com seus grandes prédios e estabelecimentos comerciais, erguidos com a participação da presença germânica. “É esta perseverança, a geradora do supposto 'perigo allemão', que as grandes potências procuraram fazer nascer dos lábios e do coração do Kaiser, para levar-nos a boycottage dos productos que os vasos da marinha mercante conduzem de Hamburgo para os nossos portos" (grifo nosso).

E o texto assim terminava, como uma exortação:

Queremos a livre concurrencia no commercio externo, garantidora da liberdade nacional; e assim como o nosso amor ao paiz nos leva a abrir os nossos portos para todos os povos, sem distincção de raça ou de religião, proporcionando garantia aos direitos e hospitalidade aos colonos, também o mesmo sentimento não deixará que medrem explorações condemnaveis ou desejos criminosos. A Germania é a terra do Saber e da Industria; nos a amamos e della queremos a lição dos seus livros, os braços de seus filhos e os productos das suas fabricas sem similares no paiz. E a admiramos também por que é a pátria da liberdade, que o reverbero do gênio de Goethe assim insculpio: "somente alcança liberdade e vida, quem tem de as conquistar dia por dia."Aos marinheiros da canhoneira Panther as saudações effusivas do Diário. ${ }^{53}$

\footnotetext{
${ }^{51}$ Ibidem, p. 235-236.

${ }^{52}$ STROBEL, op. cit., p. 125.

${ }^{53}$ Diário da Tarde, Curitiba, 4/11/1905. No mesmo dia 4 de novembro, além das notícias a respeito do extenso programa que a cidade preparou recepcionando a tripulação do Panther, do texto Germania, mencionado, também se publicava um artigo de M. I. Carvalho de Mendonça, intitulado "Os Allemães nos Estados do Sul do Brasil". Era quase uma réplica ao artigo "Allemães no Brasil", publicado no Jornal do Commércio, no Rio de Janeiro.
} 


\section{O "perigo alemão", uma construção francesa?}

As considerações acima anunciam um "perigo alemão". No entanto, feitas as contas, havia mesmo um perigo alemão? o que chama a atenção é, sim, a existência de um discurso que, muitas vezes, era veiculado no Brasil, e este remetia à criação de uma Alemanha Austral, em detrimento dos países cujos territórios compunham o Cone Sul da América ${ }^{54}$, discurso enfatizado pelos pangermanistas que, no limite, reivindicavam, como W. Wintzer, o Anschluss dos alemães da América Latina. ${ }^{55}$

Sem descartar Estados Unidos e Grã-Bretanha, cada um com seus motivos para denunciar o avanço alemão, eram os franceses - impregnados de teutofobia - que se manifestavam mais duramente a respeito. ${ }^{56}$ Após 1870, “a Alemanha torna-se uma 'entidade metafísica', um país formidável escarnecendo sobre os reconhecidos valores internacionais: a título coletivo, os alemães são julgados culpados dos mais funestos modos de agir, em nome do eterno germanicismo hegemônico e perverso" (Ibid. p. 256)..$^{57}$

Nossa ênfase, aqui, não se refere somente ao fato de que a relativa concentração das colônias germânicas era visível demográfica e geograficamente. Espraiando-se do Paraná até o Cone Sul, assombravam alguns observadores e, dessa maneira, perguntamo-nos até que ponto a opinião francesa não influenciava parcela importante da elite brasileira. ${ }^{58}$ De um modo ou de outro, viajantes dessa nação confirmavam o temor de muitos brasileiros de que uma Alemanha na América Latina, agregando o Brasil Meridional, o Uruguai e parte da Argentina, era plano do Kaiser Guilherme II.

Alguns franceses, visitando o Brasil, alertaram seus leitores sobre o perigo da presença dos alemães. De um lado, recorrentemente narravam

\footnotetext{
${ }^{54}$ Dreher observa que o Reich "redescobria", no desenvolvimento de suas políticas imperialistas após Bismarck (1871), os emigrantes alemães e descendentes localizados no Além-Mar, em especial aqueles das partes mais meridionais da América do Sul: "O Sul do Brasil deverá ser substitutivo para as colônias que a Alemanha não possui”. DREHER, Protestantismo de imigração no Brasil: sua implantação no contexto do projeto liberal-modernizador e as consequências desse projeto. In: DREHER, M. (org.). Imigrações e história da Igreja no Brasil. Aparecida/sp: Editora Santuário, p. 127.

${ }^{55}$ BLANCPAIN, op. cit., p. 267-268.

${ }^{56}$ Ver, a respeito, a obra CHÉRADAME, op. cit.

${ }^{57}$ A respeito, ver também OLIVEIRA, op. cit., p. 50-51.

${ }^{58}$ Sobre os interesses e as relações das grandes potências européias (Alemanha, Inglaterra e França) com o Brasil, CAMARGO, Haroldo Leitão. O perigo alemão: um fenômeno de opinião nacional. História e-história. Campinas, Unicamp, 2006. Disponível em: http://www.historiaehistoria.com.br/materia. $\mathrm{cfm}$ ?tb=historiadores\&id=35 (texto sem indicação de páginas).
} 
sobre um país paradisíaco, no qual existiam alemães que constituíam fator de inquietação - aliás, como na Europa. ${ }^{59}$ Um destes viajantes, Étienne de Rancourt, passou seis meses no Brasil, de agosto de 1899 a janeiro de 1900. De passagem por Curitiba, apreciou bastante a capital do Paraná, mas observou que os alemães tentavam estabelecer sua supremacia comercial contra os franceses, belgas e britânicos. ${ }^{60}$ Além disso, o viajante agregava que (coerentemente com algumas ideias nacionalistas antissemitas francesas), "como a raça israelita, a raça alemã é essencialmente invasora". ${ }^{61}$

Nas entrelinhas dos seus textos publicados antes da guerra, e muitas vezes explicitamente, os viajantes exteriorizavam uma "germanofobia" que se traduzia em preconceitos, o que os levava a descrever os imigrantes alemães de forma estereotipada: o alemão era visto como prático, utilitarista, materialista e realista; grande e pesadão, amante da cerveja e "bon vivant", inassimilável e racista. ${ }^{62}$ Enfim, mais ou menos nuançados, mais ou menos caricaturais, esses textos iam num mesmo sentido, denunciando o perigo germânico. Com efeito, existem fartas indicações de que o "perigo alemão" no Brasil foi uma construção francesa: no imaginário brasileiro dos franceses, tem seu lugar os alemães no país - por exemplo, sob a forma recorrente e fantasmagórica de um Brasil germanizado. ${ }^{63}$

Lembramos, como Jean-Pierre Blancpain, que a inteligentsia latino-americana foi, majoritariamente, francófila até a Segunda Guerra Mundial. Dessa forma, emprestou bastante do arsenal francês da "germanofobia" para refutar as teses neutralistas de certos espíritos crioulos de educação alemã ou simplesmente sensível aos fatores alemães para o progresso de seus próprios países. ${ }^{64}$ Ou seja, se eram ou não reais as preocupações dos "anti-alemanistas", ou as ambições imperiais alemãs naquilo que se referia ao Cone Sul da América Latina, o fato é que parcela da opinião pública brasileira acreditava que esses e outros sinais (incentivo à emigração alemã e a

\footnotetext{
${ }^{59}$ TETTAMANZI, Régis. La "germanité” face à l’héritage latin des Amériques: la construction française du “péril gérmanique” au Brèsil 1900-1940. In: ROLLAND, Denis (coord.). Archéologie du sentiment en Amérique latine. L'identité entre mémoire et histoire; XIX ${ }^{\mathrm{e}}$-XXI ${ }^{\mathrm{e}}$. siècles. Paris: L”Harmattan, 2005. p. 170.

${ }^{60}$ Imaginamos que Rancourt estava se referindo ao comércio internacional, pois em Curitiba temos registros de poucos ingleses, e não temos documentada a presença de comerciantes belgas e franceses.

${ }^{61}$ Ver também as observações de Claude Eylan a respeito de Curitiba e os alemães (TETTAMANZI, op. cit., p. 169).

${ }^{62}$ Ibidem, p. 164-178.

${ }^{63}$ Ibidem, p. 163-184.

${ }^{64}$ BLANCPAIN, op. cit., p. 257.
} 
propaganda pangermanista) indicavam interesses expansionistas da Alemanha, principalmente a partir dos anos de $1890 . .^{65}$

É assim que parte da imprensa brasileira demonstrava há algum tempo a desconfiança em relação às intenções do Reich, apoiando as políticas dos países que constituiriam a Entente Cordiale; dessa opinião, eram poucos os que minimizavam o "alemanismo" no Brasil Meridional. Todavia, outros, talvez mais influenciados pelo ambiente de uma cultura imigrante, subestimavam a questão. Foi assim que o Diário da Tarde, geralmente simpático à causa dos "alemães", publicava uma matéria em agosto de 1899 a respeito do perigo de a Alemanha anexar parte do Brasil, da qual destacamos o seguinte trecho:

Enfim, as nossas relações [com a Alemanha] tem sido de correta amizade, como pois, se justifica a nossa suceptilibidade? Justifica, dizem, o fato de os alemães não se preocuparem com a língua do país. Os alemães entre si falam alemão, o mesmo o fazem em família, porém, não é assim que também procedem os franceses, italianos, polacos? O que se exige e deve-se fazer com energia é o uso da língua do país em todos as relações oficiais e negocios públicos.... ${ }^{66}$

Portanto, é nesse contexto - provavelmente após as crises provocadas pelo Panther - que Gustav Hermann Strobel escreve, em suas memórias:

Quando um repórter inglês ou francês, irresponsável resolve escrever sobre o chamado "Perigo alemão no Brasil", esse assunto é comumente matéria para ser transcrita por diversos periódicos no Brasil. E se não fossem prontamente rebatidos por articulistas nacionais, de espírito arejado e bom senso, certamente pelos seus autores, que obviamente é envenenar e indispor os imigrantes alemães com os nacionais (sic). A ralé certamente aproveitaria a menor oportunidade para saquear e destruir os estabelecimentos e propriedades destes alemães. Estas pessoas que se dispuseram a defender os nossos patrícios não devem ser esquecidos por nós. Entre eles devo citar o senhor Alcides Munhoz. ${ }^{67}$

$\mathrm{O}$ ataque é a melhor defesa? o fato é que, como mencionamos, o clima no início do século já traduzia, tomando emprestada a expressão de Silvio Romero, certo "anti-allemanismo". Se Alcides Munhoz, mencionado acima por Strobel, reconhecia ser o notável desenvolvimento industrial paranaen-

\footnotetext{
${ }^{65}$ SEYFERTH, Giralda. A conflituosa história da formação da etnicidade teuto-brasileira. In: FIORI, N. A. (org). Etnia e educação: a escola "alemã" do Brasil e estudos congêneres. Florianópolis: Ed. da UFSC; Tubarão: Editora Unisul, 2003, p. 42.

${ }^{66}$ Diário da Tarde, Curitiba, 2/8/1899.

${ }^{67}$ STROBEL, op. cit., p. 138.
} 
se fruto da contribuição imigrante alemã, ${ }^{68}$ Nestor Vitor dos Santos ${ }^{69}$ opinava mais criticamente. Sem desmerecer a importância dos comerciantes e industriais de origem alemã, referia-se que padeiros e açougueiros, "teutões, na sua grande maioria; fazem uma espécie de trust desses dois negócios, com desvantagem para a população". ${ }^{70}$ Entretanto, no que dizia respeito ao "allemanismo", este cronista, em 1912, exasperava-se:

Tornava-se por fim irritante a quem ali demorava a segregação em que, a respeito de quase tudo, vivia aquela gente do elemento nacional. Era raro ver-se até um simples filho de alemães, já nascido no Brasil, aliar-se a uma moça brasileira. Eles só liam jornais impressos em tipos góticos; publicavamse uns quantos desses em Curitiba. As crianças só freqüentavam colégios germânicos, onde não havia o ensino do português. Assim, bem comumente, velhos imigrantes, que já estava naquela terra havia dezenas de anos, mal podiam expressar alguma coisa em nossa língua, e até rapazes e moços de sua prole falavam português com muita imperfeição e deficiência. Nas ruas, freqüentemente, de passagem, ouviam-se louros bandos de crianças que estavam a brincar tagarelando "yas" e "nichts", parece que numa absoluta ignorância do nosso idioma. Acontecia dirigirmo-nos a uma moçoila ou a uma dona de casa pedindo qualquer informação e vemos com dolorosa surpresa que não éramos entendidos. Se tomávamos um carro, estávamos na contingência de fazer, as vezes, nossa viagem sem trocar palavra com o cocheiro porque este só sabia alemão. ${ }^{71}$

Foi nesse ambiente que o já referido imigrante alemão em Curitiba escrevia sobre suas memórias; revia a história contada por seus pais e sua experiência, já madura, como filho de imigrantes e como imigrante e, talvez melhor, como teuto-brasileiro. ${ }^{72}$ Enfatizando, uma situação muito especial, se

\footnotetext{
${ }^{68}$ MUNHOZ, Alcides. O Sr. Sylvio Romero e o allemanismo no Sul do Brasil: o Paraná. Curitiba: Oficinas de Artes Gráficas de Adolpho Guimarães, 1907, p. 5.

${ }^{69}$ Nestor Vitor, nascido em Paranaguá em 1868, foi, entre outras virtudes literárias, cronista.

${ }^{70}$ SANTOS, Nestor Vitor dos. Terra do futuro (impressões do Paraná) (2ª. ed.). Curitiba: Prefeitura Municipal de Curitiba, 1996, p. 86.

${ }^{71}$ Ibidem, p. 77.

72 "A categoria Deutschbrasilianer aparece na segunda metade do século passado para definir o duplo pertencimento - à etnia alemã e ao Estado brasileiro na qualidade de cidadão. (...) A comunidade étnica teuto-brasileira foi definida objetivamente por seus membros a partir do uso cotidiano da língua alemã, da preservação de usos e costumes alemães (...), da intensidade da vida social expressa pelas muitas associações que assumiram forte caráter étnico (...) (SEYFERTH, Giralda. A identidade teuto-brasileira numa perspectiva histórica. In: MAUCH, C.; e VASCONCELLOS, N. (org). Os alemães no Sul do Brasil: cultura, etnicidade, história. Canoas: Ed. ULBRA, 1994. p. 15). Esta é a visão do historiador, pretendendo compreender o passado. Naquele presente, entretanto, havia aqueles que não concordavam com a "denominação teuto-brasileira aos descendentes de allemães (que) não se justifica nem perante a lei, nem em face do sentimento cívico que deve ser definido e único. Com a permanência de semelhante situação moral, fica o chamado teuto-brasileiro com duas meias pátrias e, conseqüentemente, com duas portas abertas para
} 
focarmos o clímax assinalado pelos acontecimentos e pelas pressões populares que contribuíram para a participação do Brasil ao lado da Entente na Grande Guerra, a partir de 1917. Um ambiente no qual se compreende um natural reforço da etnicidade, caracterizando a passagem do século XIX para o século XX. Problema que dá o que pensar, tendo em vista o esforço da historiografia no sentido de privilegiar as questões étnicas no período entre as duas Guerras Mundiais.

É preciso não esquecer que, na época em que escreve Gustav Hermann Strobel, estava-se ainda muito próximo da derrota traumática da França em 1870. Mas, se a vitória prussiana contribuiu para fortalecer a germanofobia francesa, foram justamente esse triunfo e a resultante construção do Reich que contribuiriam a uma identidade dos imigrados germânicos, fortalecendo as relações entre eles mesmos e a velha pátria. ${ }^{73}$ Por ocasião da visita dos tripulantes do Panther a Curitiba, na noite do sábado, 5 de novembro de 1905, "realizou-se no salão Hauer o grande festival dedicado a illustre officialidade allemã". O diário A República relatou a extensa programação, salientando lá pelas tantas a representação "do quadro patriótico de R. Ländau" concernente ao país dos Niebelungen. O jornal empenhou-se em relatar a "interessante lenda" e como ela era apropriada pelos eventos relativos à unificação alemã:

o imperador Barbarroxa, retirado desde há mil annos n'uma caverna mysteriosa, se achava immerso em profundo somno ao lado da coroa imperial, que devia ser dada um dia ao monarcha mais digno. O velho imperador dos germanos, guardado alli por dois guerreiros de elmo e montante e sobre cujos escudos a cruz negra da Lithuania se destacava com um canto de heroísmo a celebrar as antigas glorias germânicas. Finalmente, em 1870, a Germania victoriosa se apresenta na caverna de Barbarroxa para que este lhe restitua a coroa imperial. O velho monarcha germânico ergue se do seu lethargo e, ao rebrilhar das espadas nuas que o saúdam, depõe sobre a loira cabeça da Germania ajoelhada aos seus pés o áureo diadema. Enorme enthusiasmo provocou este quadro, cujo final foi freneticamente saudado. ${ }^{74}$

$* * *$

a defecção, para a traição. [...]. Assim, a expressão teuto-brasileira sobre ser anphibia é a todo ponto perigosa naquilo que diz respeito a integridade do carácter nacional. Chegamos ao instante de definir posições: ou brasileiro ou allemão. Pão pão, queijo queijo (Commércio do Paraná, Curitiba, 21/4/1917). Ver também FABRIS, Pamela. "Enquanto nós dormimos o alemão trabalha": relações entre a comunidade étnica germânica e a sociedade curitibana (1870-1918). Curitiba, 2009. Monografia. Curso de História, UFPR.

${ }^{73}$ BLANCPAIN, op. cit., p. 255.

${ }^{74}$ A República, Curitiba, 6/11/1905, sem grifo no original. 
Já mencionamos que Gustav Hermann e sua esposa viajaram à Alemanha em 1913, para tentar curar o seu filho doente. Sem entrar no mérito da decisão do casal, o fato é que os Strobel estavam imersos, em Leipzig, num certo clima de tensão. Em correspondência enviada a Franz, Bertha e Kurt Strobel - filhos, nora e neto -, Gustav Hermann escreve cartas e cartões postais. De 3 de julho de 1913 a 24 de julho de 1914, o teor é sempre doméstico, familiar, ressaltando o estado de saúde do filho internado. Na última carta, entretanto, finaliza comentando: "Desde ontem e hoje só se falava de guerra entre a Áustria e a Sérvia. Já está em tempo que as provocações dos eslavos e franceses recebam uma resposta adequada (sem grifo no original)". Nas cartas que se seguem, ${ }^{75}$, continuam os assuntos familiares, entremeados de menções sobre as dificuldades dos correios para a América do Sul em função da Guerra. Uma, em especial, diz respeito à posição dos "brasileiros" que, "como na guerra de 1870/71, estão ao lado dos franceses; nós devemos no futuro nos lembrar disto". ${ }^{76}$ Provavelmente antes disso, já havia se manifestado em suas memórias - ao que tudo indica, referindo-se novamente aos franceses:

também os jacobinos (que pregam o ódio aos estrangeiros) procuraram acirrar os ânimos contra os alemães e descendentes de outras nacionalidades; esses não devem ser olvidados para na hora de eleições, se fazer justiça aos que defendem os que trabalham pelo progresso desta terra". ${ }^{77}$

Parece-nos, portanto, que o engajamento de Gustav Hermann é total, e sua identidade étnica estava impregnada de uma manifestação antieslava, mas, mais do que isso, de uma reação defensiva e "francófoba".

Tal tipo de opinião, seguramente, teria respaldo no Brasil entre boa parte da comunidade étnica. De modo que o Império tornava-se cada vez mais onipresente nas comunidades alemãs fora da Europa - o que variavelmente encarnava-se pelo pangermanismo ${ }^{78}$ e por um nacionalismo exacerbado -, assegurando proteção aos, segundo alguns, "americanos acidentais e provisórios". A interpretação do direito de solo vinha, evidentemente, colocar mais lenha na fogueira, radicalizando-se entre dois nacionalismos: "a ideologia do partido pangermânico expansionista e o nacionalismo

\footnotetext{
${ }^{75}$ As cópias que temos, traduzidas, terminam em 30/9/1916.

${ }^{76}$ Correspondência datada em Leipzig, 10/12/1914.

${ }^{77}$ STROBEL, op. cit., p. 138, sem grifo no original.

${ }^{78}$ No Brasil, 20 mil teuto-brasileiros teriam sido identificados como pangermanistas em 1900, número que deveria ter aumentado até a Primeira Guerra (SANTANA, op. cit., p. 245).
} 
republicano militante"79 - este, de inspiração francesa e positivista. Essas questões, articuladas ao fato de que o "dom da naturalização", num contexto em que o naturalizado não tinha os mesmos direitos do nascido no Brasil, não contribuíam para amenizar o problema. ${ }^{80}$ Sem dúvida, teorizar sobre isso e outras questões relacionadas era exercício costumeiro entre a intelligentsia que se desenvolveu nas colônias imigrantes, que advogava a manutenção de um estatuto verdadeiramente teuto-brasileiro, contestando e criticando o jus solis republicano. ${ }^{81}$

Em agosto de 1914, o Diário da Tarde informava que as "colônias alemãs" estavam reclamando da postura da imprensa brasileira sobre a Guerra, pois, aos olhos daquelas, as notícias não eram neutras e sim a favor dos aliados, em especial dos franceses:

Esse descontentamento tem-se manifestado também em Coritiba, cujos órgãos de publicidade são accusados de parcialidade contra o império germânico ao relatar os acontecimentos. Em relação a alguns jornaes de outras terras, essa queixa tem razão de ser, embora não seja extranhável que a imprensa do Brasil tenha decidido pendor pela nação franceza, que além de gloria da raça latina, é o pharol da nossa intellectualidade. Mas quanto a imprensa do Paraná a absoluta injustiça por parte da colônia allemã. [...]. Temos razões fortíssimas para amar a França; por outro lado, ao concurso dos allemães devemos a grandeza do sul do Brasil; portanto, sejamos neutros no assumpto. ${ }^{82}$

\section{À guisa de conclusão}

Com as informações fornecidas pelos registros de casamentos, há tempos foi calculada a percentagem de endogamia ocorrida na Comunidade Evangélica Luterana de Curitiba, que se manteve, no período de 1870 a 1939, em torno de $87 \%$. Em especial, observou-se que, no período concernente às décadas de 1890, 1900 e 1910, essa endogamia beirava praticamente um número absoluto de casamentos..$^{83}$

\footnotetext{
${ }^{79}$ CAMARGO, op. cit., O texto não indica páginas.

${ }^{80}$ BLANCPAIN, op. cit., p. 247.

${ }^{81}$ A frase "nós queremos ser e permanecer homens alemães, (e) honestos e bons cidadãos brasileiros" (originalmente em alemão), mencionada no número 87 do jornal curitibano DER KOMPASS (1937), sintetizava ideia recorrente que se veiculava entre os teuto-brasileiros, já no contexto que estamos analisando (apud WILLEMS, A aculturação dos alemães no Brasil. Estudo antropológico dos imigrantes alemães e seus descendentes no Brasil (2a ed). São Paulo: Cia. Editora Nacional, 1980, p.152-5). Ver, a respeito, SEYFERTH, Nacionalismo... op. cit., p. 56.

${ }^{82}$ Diário da Tarde, Curitiba, 17/11/1914.

${ }^{83}$ NADALIN, Sergio Odilon. A origem dos noivos nos registros de casamento da Comunidade Evangélica Luterana de Curitiba; 1870-1969. Curitiba, Dissertação, Mestrado, Universidade Federal do Paraná, 1974, p. 74-84; 164-184.
} 
Decorrem daí algumas questões, uma vez que é contínua, durante todo o período, a imigração alemã, bem como seu peso político-cultural, mormente no Sul do país. Haveria relação entre a concentrada endogamia na virada do século XX em Curitiba com uma conjuntura dominada pelos debates a respeito das questões "assimilacionistas" que estavam ocorrendo no Brasil, à sombra da influência dos pangermanistas? Até que ponto a endogamia refletiria um retraimento étnico na comunidade, também influenciado pelos acontecimentos que se desenvolviam na direção da Primeira Grande Guerra?

Concordando com as críticas de Emilio Willems, registradas já há bastante tempo, a respeito da utilização do casamento como indicador de "assimilação" ${ }^{\text {, }}$ tentou-se ampliar a problemática, buscando indicadores relativos à conjuntura, tais como a escolha dos nomes de batismo. ${ }^{85}$ Assim sendo, procuramos as evidências mencionadas numa amostra representada pelos processos de nominação entre os descendentes dos mencionados Christian August Strobel e sua mulher, Christine Friederike. ${ }^{86}$

Na pesquisa concernente, comparando-se os comportamentos de três gerações no âmbito da linhagem Strobel em Curitiba, é a segunda, dos filhos e sobrinhos de Gustav Hermann (portanto, todos netos do casal fundador), que - batizando os seus filhos entre 1899 e 1926 - escolheram majoritariamente não só nomes oriundos da bagagem imigrante, mas principalmente nomes alemães muito antigos. Evidentemente, trata-se de um tema complexo, que exige mais pesquisas a respeito. Entretanto, é possível aventar uma orientação mais conservadora dos netos de Christian Strobel, que fariam escolhas e opções direcionadas segundo as tendências conjunturais

\footnotetext{
${ }^{84}$ WILLEMS, op. cit., p. 322.

${ }^{85}$ NADALIN, A constituição das identidades nacionais... op. cit. A respeito dos processos de nominação considerando questões étnicas, ver também MERCER, José Luiz da Veiga \& NADALIN, Sergio Odilon. Um patrimônio étnico: os prenomes de batismo. Topoi, 9(17):12-21, jul-dez. 2008. (Revista online: http://www.revistatopoi.org/numeros_anteriores/topoi17/topoi_17_-_artigo2_-_um_patrim\%C3\%B4nio_\%C3\%A9tnico. pdf); NADALIN, Sergio Odilon, 1978. Une paroisse germanique au Brésil; la Communauté Évangélique Luthériènne à Curitiba entre 1866 et 1969. Paris, Thèse, Doctorat $3^{\mathrm{e}}$ Cycle, EHESS. p. 179-198; NADALIN, Sergio Odilon. Um viés determinado pela etnicidade: os nomes de batismo (registros paroquiais de uma comunidade luterana, séculos XIX e XX). In: BASSANEZI, M. S. C. B. \& BOTELHO, T. R. (org.). Linhas e entrelinhas: as diferentes leituras das atas paroquiais dos setecentos e oitocentos. Belo Horizonte: Veredas \& Cenários, 2009. NADALIN, Sergio Odilon. Atribución de nombres de bautismo: inmigrantes alemanes, identidad étnica y construcción de um mundo simbólico (Curitiba, Brasil: 1866-1987). In: BESTARD, Joan; e GARCIA, Manuel Pérez (orgs.). Familias, valores y representaciones (1 ${ }^{\text {a }}$. ed;). Murcia: Editum (Ediciones de la Universidad de Murcia), 2010. p. 367-381 (Texto integral em português: http://nuevomundo.revues. org/index28672.html.).

${ }^{86}$ NADALIN, Sergio Odilon. Identidade e parentesco na construção e desconstrução da cultura teuto-brasileira (1876-1973). I Congresso Internacional REFMUR (Rede Famílias Murcia) - "Famílias: complexidades do passado e do presente”, em Múrcia, Espanha, 1-2 fevereiro de 2011. Texto inédito.
} 
observadas nos casamentos na comunidade. Ou seja, a nossa aposta é que isso reflete, conscientemente ou não, uma situação étnica evidente, nas duas primeiras décadas do século.

Por razões, a nosso ver, ainda não bem compreendidas, e

diferentemente daquilo que se costuma referir em relação aos Estados Unidos, onde os imigrantes alemães se teriam inserido numa realidade caracterizada pelo melting pot, ao qual teriam aderido de forma rápida e maciça (...), aqui, os imigrantes vindos da Alemanha, em geral, foram apontados como aqueles que, entre os grupos de imigrantes de maior expressão numérica - e ao lado dos japoneses -, ter-se-iam mostrado como os mais resistentes à integração, à miscigenação, à assimilação, mantendo suas características étnicas nas regiões que ocuparam, continuando a cultivar, de forma persistente, a língua e os modos de vida alemães. ${ }^{87}$

O que observamos na pesquisa analisada neste texto é que a opinião pública brasileira, manifestada em alguns jornais pesquisados, parecia estar dividida. Poder-se-ia identificar clivagens regionais? Apesar das notícias geralmente elogiosas veiculadas por jornais curitibanos, e o que pareceria uma clara tomada de posição do Jornal do Commercio, do Rio de Janeiro, não sabemos o quanto a distância das colônias teriam influenciado opiniões mais ou menos favoráveis à imigração alemã e à concentração relativa das colônias no Sul brasileiro. Afinal, salvo a alguns membros de uma elite educada à francesa, qual o interesse que poderiam ter as colônias de origem germânica para, digamos, a opinião nordestina ou do Norte? Por outro lado, a proximidade poderia levar a reações, tais como a aparente agitação do governo da Província de Santa Catarina em relação ao incidente provocado pelo Panther, no porto de Itajaí. ${ }^{88}$

Para resumir, é possível depreender que havia, de maneira geral, um embate entre uma imprensa teuto-brasileira, de diversos matizes, e uma imprensa "nacional", o que gerava conflitos de opiniões no qual se debatia o imigrante e "teuto-brasileiro", Gustav Hermann Strobel. Em diversos trechos das suas memórias, fosse explicita ou implicitamente, o problema se revelava.

Artigo recebido para publicação em: 12/04/2013

Artigo aprovado para publicação em: 17/06/2013

${ }^{87}$ GERTZ, René E. Brasil e Alemanha: os brasileiros de origem alemã na construção de uma parceria histórica. Textos de História. Revista do PPGHIS da UnB. Brasília: UnB, 16(2), 2008, p. 119.

${ }^{88}$ Ver a matéria publicada pelos Annaes, do Rio de Janeiro, em janeiro de 1906. 